\title{
The DCRS: Dynamic compaction resistance sintering. A flash sintering process with a dynamic loading ability
}

\author{
P. Acquier ${ }^{1,2,3}$, S. Lemonnier ${ }^{1}$, E. Barraud ${ }^{1}$, A. Rusinek², T. Grosdidier ${ }^{3}$, N. Allain-Bonnasso ${ }^{3}$, \\ and C. Terner ${ }^{1}$ \\ ${ }^{1}$ ISL - French-German Research Institute of Saint-Louis, 5 rue du Général Cassagnou, 68300 Saint-Louis, \\ France \\ ${ }^{2}$ National Engineering School of Metz (ENIM), Laboratory of Biomechanics, Mechanics, Polymer, \\ Structures (LaBPS), 1 route d'Ars Laquenexy, 57078 Metz Cedex 3, France \\ ${ }_{3}^{3}$ LEM3 - Laboratoire d'Étude des Microstructures et de Mécanique des Matériaux, CNRS UMR 7239, \\ Lorraine University, Ile du Saulcy, 57045 Metz Cedex 1, France
}

\begin{abstract}
A homemade powder processing device combining Joule heating and dynamic compaction is presented. This device has been tested at temperatures as high as $1850{ }^{\circ} \mathrm{C}$ with heating rates up to $1000^{\circ} \mathrm{C} / \mathrm{min}$. A detailed description of this device is given here followed by mechanical response and thermal validation tests. This highlights the reproducibility of the results on both the thermal and mechanical point of view.
\end{abstract}

\section{Introduction}

The powder metallurgy route is an effective way for processing a large spectrum of materials ranging from metals to ceramics and their composites.

Free sintering, pressure assisted sintering, resistive sintering, are among the powder processing techniques that can be used to obtain dense materials with tailored properties. Concerning resistive sintering, the association of Joule heating with high heating rate $\left(>500^{\circ} \mathrm{C} / \mathrm{min}\right)$ with pressure application (around tens of $\mathrm{MPa}$ ) is used for powder densification. A recent review article of [1] shows that the Resistive Sintering (RS) techniques, among which the so called Spark Plasma Sintering (SPS), have demonstrated high efficiency for (i) improving materials sinterability, and (ii) consolidating many materials such as metals, ceramics, polymers and composites.

In the RS processes, the application of a quasistatic pressure is used to control the microstructural state of the sintered powders. It was shown [2] that the application of a pressure authorizes to decrease the sintering temperature and thus limit the grain growth of zirconia powder. Higher pressure would enable the use of lower sintering temperature. It has been demonstrated [3] that slower grain growth rates and better homogeneity can be obtained on alumina by using a two step pressure procedure: low pressure during heating and high pressure during the subsequent sintering stage. This was explained by the combination of improved gas evacuation facilitated at low temperature with plastic deformation enhanced at high temperature.

Powder consolidation techniques involving very high loads and/or high velocity loadings have also been developed such as explosive consolidation [4], falling ram compaction [5], or impact with a Split Hopkinson Pressure Bar (SHPB). The interest is that the deformation regime becomes adiabatic when high strain rates $\left(\dot{\varepsilon}>10^{2} \mathrm{~s}^{-1}\right)$ are employed. This leads to an increase in the local temperature, thus helping the material consolidation. This effect is used to compact hydroxiapatite powder with a SHPB [6] without any other thermal input than the in-situ adiabatic heating. Green compacts with higher densities than quasistatically compacted ones were also obtained [7] using a SHPB as a mean of compaction.

The goal of our research is to use the combination of resistive sintering together with dynamic loading by SHPB for consolidating powder with improved efficiency. Combining high speed heating rate with Joule effect and dynamic compaction with a SHPB has already been done [8] but with a totally different purpose. These authors have tested solid materials in a dynamic range under metastable temperature conditions. However, to our knowledge, this kind of device has never been used for material sintering. This requires that many modifications are to be implemented to reach this new objective.

The process described in this paper, which combines flash sintering and dynamic compaction, is called DCRS: Dynamic Compaction Resistance Sintering.

\section{Specific design considerations}

The new DCRS device has been developed at ISL. It consists in adapting a resistive heating device on top of a SHPB. Figure 1 gives a schematic drawing of the DCRS device. The technique will be discussed in this paper.

The DCRS device requires precise thermal and mechanical controls. The thermal part consists of the power supply, the heating rig as well as the temperature control and regulation by thermocouples and/or pyrometers. The mechanical part is given through the modification of a SHPB device adapted for providing quasistatic loading and dynamic impact during the thermal cycles and ensures powder compaction and sintering. Both of these functional parts are controlled and monitored precisely with a computer controlled interface.

The DCRS process uses the concept of the SHPB device for dynamic loading. Therefore it has all its 


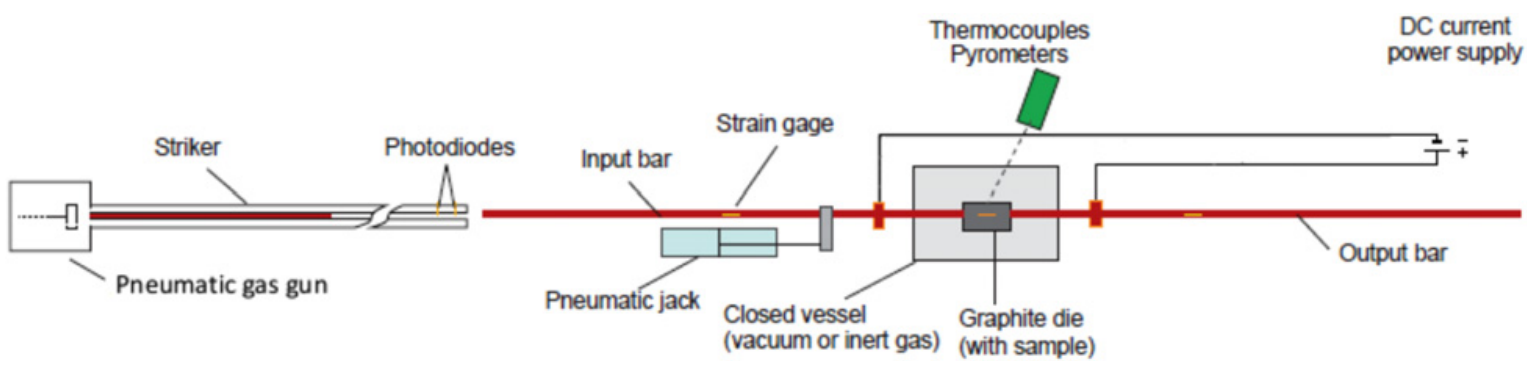

Fig. 1. Sketch of the DCRS device developed for dynamic compaction.

constitutive elements: input and output bars, a pneumatic gas gun used to propel a striker and sensors such as photodiodes for the striker speed measurement and strain gauges.

The classic use of a SHPB device is for dynamically testing solid materials. During this dynamic compression test, a sample is sandwiched between the input and the output bars. The input bar is then submitted to an impact through the striker, which is shot with the pneumatic gas gun. This impact on the input bar creates an incident uniaxial elastic wave that propagates toward the material. One part of this wave is reflected on the input bar and the other part is transmitted through the sample. Samples are then subjected to an adiabatic heating with a strain rate typically ranging from $8.10^{2}$ to $10^{4} \mathrm{~s}^{-1}$.

The DCRS device, developed at ISL, uses the same mechanical loading and analysis where strain wave propagation can be recorded via strain gages. In addition to this dynamic loading, a pneumatic jack has been added to apply a quasistatic load.

For material sintering application, the aim of this device is to combine the heating and loading stages of a conventional SPS sintering with the addition of one or multiple impacts during consolidation. Different thermomechanical cycles can also be applied.

\subsection{Heating stage}

The temperature is monitored through blind holes drilled in the graphite matrix using both thermocouples and/or pyrometers. The blind hole allows the temperature to be measured as close as possible to the sintering powder.

A DC current transformer $(50 \mathrm{~V}, 300 \mathrm{~A})$ enabling resistive heating is connected to the SHPB bars. Focusing all the Joule heating effect on the graphite and powders was done by using copper Hopkinson bars having very low resistivity compared to graphite.

As for most conventional RS sintering techniques, the powder is consolidated within graphite tools (die and punches made of graphite grade 2333, graphite folds made of Papyex, Mersen). Graphite has been chosen because of its outstanding temperature resistance (up to $2200^{\circ} \mathrm{C}$ ) and its very low coefficient of thermal expansion.

The DCRS has already been tested at temperatures as high as $1850^{\circ} \mathrm{C}$ and for heating rates up to $1000^{\circ} \mathrm{C} / \mathrm{min}$. The sintering kinetics is an important parameter to be controlled for optimization of the processing conditions. It can be followed here in situ by using a micrometric laser sensor for a dilatometric measurement.
An atmospheric chamber has been designed at ISL for the following reasons: (i) to work under vacuum or neutral / reactive atmosphere, (ii) to control of the thermal cycles under heating as well as cooling, (iii) to confine the hot area in the vicinity of the consolidating sample. Two bar chillers were placed on both sides of the Hopkinson bars to avoid excessive heating while the motion of the bars remained possible, even under controlled atmosphere, with the use of dedicated vacuum rings.

\subsection{Automation}

A user friendly interface has been developed with LabVIEW ${ }^{\circledR}$ in order to monitor carefully thermal and loading cycles and record all the parameters.

- The pneumatic control allows the user to regulate very precisely $( \pm 0.01$ bar) the pneumatic gas pressure within the gun. This makes it possible to have a very reproducible striker speed. The user can also control the atmosphere in the vessel by choosing between a primary vacuum pump and different gases.

- The different sensors are:

- The micrometric laser sensor for dilatometric analysis.

- Strain gauges stuck on the input and the output bars.

- The temperatures and heating rates are controlled via a PID (Proportional-Integral-Derivative) controller.

\section{DCRS process validation}

The process needed validation on both the mechanical and thermal points of view. Mechanical validation has been done by controlling the wave propagation ensuring its control. Thermal validation has been done for temperature and heating rate control.

\subsection{Mechanical validation}

Numerical simulations have been done using the Ansys Autodyn FE code to verify that the embedded part of the output bar was not disturbing the process of elastic wave propagation. A dense aluminum sample, softer than the copper bars, was used for the simulation. The boundary and initial conditions are given in Fig. 2. The set-up was 


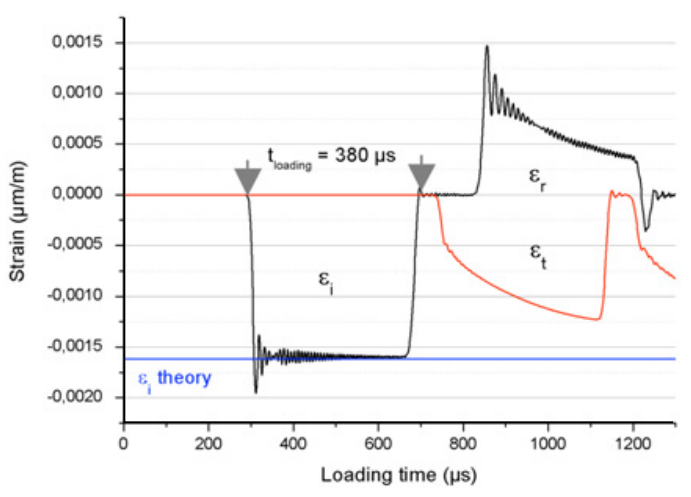

Fig. 2. Recorded waves from the simulation.

Table 1. Mechancial and Physical properties of Copper bars and striker.

\begin{tabular}{|c|c|c|c|c|c|}
\hline $\mathrm{L}_{\mathrm{p}}(\mathrm{mm})$ & $\mathrm{C}_{0}(\mathrm{~m} / \mathrm{s})$ & $\rho\left(\mathrm{kg} / \mathrm{m}^{3}\right)$ & $\mathrm{V}(\mathrm{m} / \mathrm{s})$ & $\mathrm{E}(\mathrm{GPa})$ & $\nu(-)$ \\
\hline 705.5 & 3710 & 8960 & 12 & 123.33 & 0.33 \\
\hline
\end{tabular}

modeled using an axisymmetric mesh allowing to reduce the calculation time.

To avoid the effect of friction on waves intensity, a friction coefficient equal to zero has been assumed between all contact parts for the numerical simulation [9]. To analyze the processes of elastic wave propagation, two gauges have been defined along the mesh to measure numerically the elastic waves. The distance between the gauges is in agreement with the experimental technique.

Thus, with knowledge of the impact velocity, the loading time $t_{\text {loading }}$ and the incident wave intensity $\varepsilon_{i}$

are defined using the following equations, Eq. (1)-(2).

$$
\begin{gathered}
t_{\text {loading }}=\frac{2 L_{p}}{C_{0}} \\
\varepsilon_{i}=\frac{\rho V C_{0}}{2 E}
\end{gathered}
$$

where $\mathrm{L}_{\mathrm{p}}$ is the projectile length, $\mathrm{C}_{0}$ is the elastic wave velocity, $\rho$ is the density of the bars, $\mathrm{V}$ is the striker velocity and $\mathrm{E}$ is the Young's modulus of the bars.

The mechanical properties used to simulate the elastic behavior of the bars are given in table 1 .

The values calculated using Eq. (1)-(2) were compared with numerical results. As shown in Fig. 3, a good agreement concerning the incident wave intensity and the loading time is observed. In this figure, the waves are reported corresponding to the complete process of elastic wave propagation with $\varepsilon_{r}$ the reflected wave and $\varepsilon_{t}$ the transmitted wave.

Assuming force equilibrium as it is observed, Fig. 3, $\varepsilon_{i}+\varepsilon_{r}=\varepsilon_{t}$. Therefore, the strain rate, strain and stress imposed to the specimen may be defined as follows:

$$
\begin{gathered}
\dot{\varepsilon}(t)=\frac{2 C_{0} \varepsilon_{r}(t)}{L_{p}} \\
\sigma(t)=\frac{A_{b} E \varepsilon_{t}(t)}{A_{s}} \\
\varepsilon(t)=\frac{2 C_{0}}{l_{0}} \int_{0}^{t} \varepsilon_{r}(t) \cdot d t
\end{gathered}
$$

Table 2. Johnson Cook parameters for the aluminum AA6063.

\begin{tabular}{|c|c|c|}
\hline A (MPa) & B (MPa) & $\mathrm{n}$ \\
\hline 167 & 596 & 0.551 \\
\hline
\end{tabular}

where $A_{b}$ is the bar diameter, $A_{s}$ is the sample diameter, and $l_{0}$ is the initial sample length.

The plastic behavior of the specimen tested was defined using the Johnson Cook model. Moreover, assuming:

- A non strain rate sensitivity in the range studied,

- An isothermal process and supposing $\mathrm{T}_{0}=300 \mathrm{~K}$,

the constitutive relation may be reduced to:

$$
\sigma\left(\varepsilon_{p}\right)=A+B\left(\varepsilon_{p}\right)^{n}
$$

Where $\sigma$ is the equivalent stress and $\varepsilon_{p}$ the equivalent plastic strain. A is the yield stress, $\mathrm{B}$ is a constant and $\mathrm{n}$ is the hardening coefficient. The parameters used are defined Tab. 2.

Using the constitutive equation and the wave analysis, the following results are obtained, Fig. 4.

A good agreement is observed. It can be concluded that the embedded output bar does not disturb the signal propagation. Therefore, the results obtained from this technique may be analyzed in a direct way, Eq. (3)-(5). The next step is to verify how powder material used may disturb the waves propagation as in [7].

\subsection{Thermal cycle validation}

As a very complete investigation has been recently carried out [11] on the densification mechanisms of copper under SPS, copper powder has been selected to test the efficiency of the new process.

The starting material was a spherical powder of $99.9 \%$ pure copper (metal basis), with a grain size in the range 44 to $149 \mu \mathrm{m}$ (Alfa Aesar). The heating rate was set at $50{ }^{\circ} \mathrm{C} / \mathrm{min}$ for a final sintering temperature at $850^{\circ} \mathrm{C}$. The consolidation was carried out under primary vacuum. A quasistatic loading of $12 \mathrm{MPa}$ was applied during the thermal cycle and this thermal cycle was terminated by a final dynamic loading applied at $12 \mathrm{~m} / \mathrm{s}$.

Three copper samples were sintered with the DCRS device under the same conditions to test the reproducibility of the thermal cycle. A heating ramp of $49.5^{\circ} \mathrm{C} / \mathrm{min}$ was recorded for the 3 samples while a heating ramp of $50{ }^{\circ} \mathrm{C} /$ min was programmed. The temperature was reached without any overshoot indicating the good PID regulation.

Figure 5 shows the evolutions of the sample temperature, sample shrinkage and current as a function of time. The input current imparted to the sample increases fairly linearly with temperature and drops slightly when $850^{\circ} \mathrm{C}$ are reached to keep this input temperature. After a few seconds at this temperature, the current is stopped and the striker is launched for the dynamic loading. The dilatometric shrinkage measurement provides information on the sintering behavior of the copper powder: sintering starts at about $300^{\circ} \mathrm{C}$ and almost finishes around $850^{\circ} \mathrm{C}$. The maximum sintering rate is obtained around $600^{\circ} \mathrm{C}$. This temperature domain is very much consistent with [11] 


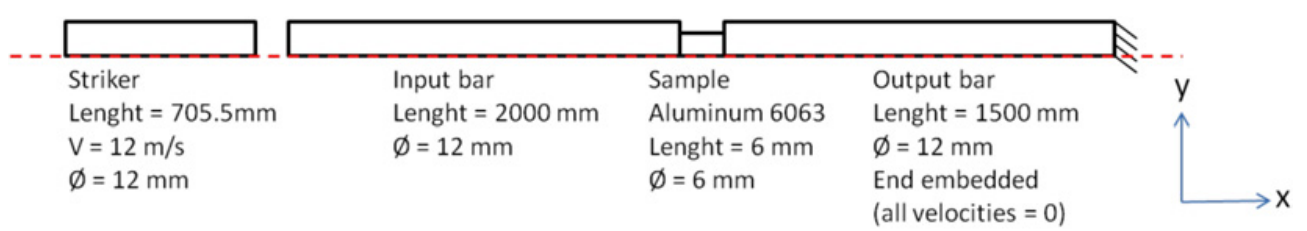

Fig. 3. Initial conditions employed for numerical simulation with copper bars and aluminum sample.

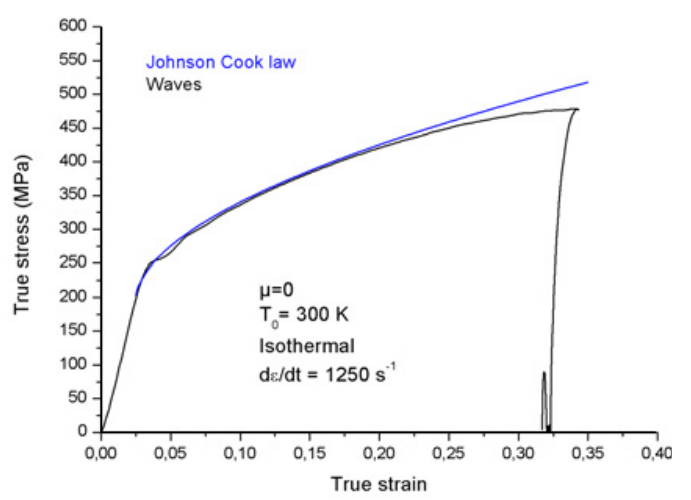

Fig. 4. Comparision between calculated true stress true strain and Johnson Cook law.

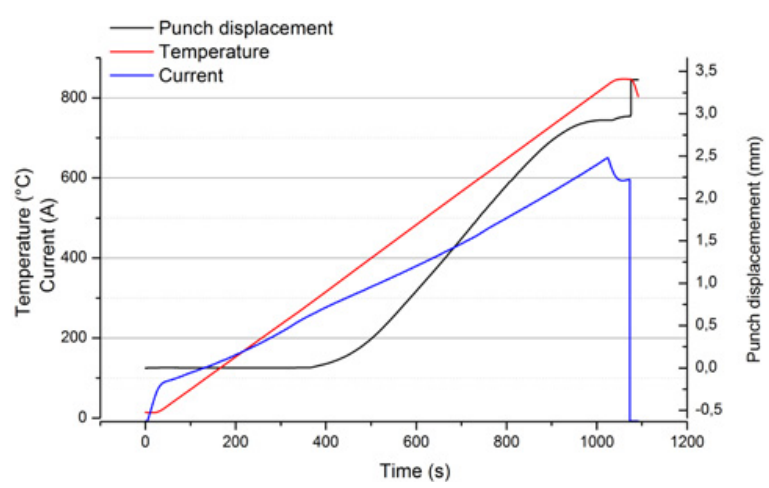

Fig. 5. Displacement, heating rate and current delivery during sintering.

for copper powder sintered by conventional SPS. In our case, the abrupt punch displacement observed at $850^{\circ} \mathrm{C}$ is due to the mechanical impact which completes the densification.

These results show the very good reproducibility of the process in terms of temperature control. The density values obtained for the 3 samples sintered with the DCRS process under the same thermo-mechanical cycle were very similar. The mean measured Archimedes's density on the 3 samples was $8.54 \mathrm{~g} / \mathrm{cm}^{3} \pm 0.02 \mathrm{~g} / \mathrm{cm}^{3}$ (the pure copper density is $8.96 \mathrm{~g} / \mathrm{cm}^{3}$ ).

These results illustrate the ability of the DCRS process which has been otherwise globally validated at different levels:

- Good temperature regulation

- Reproducibility in striker speed

- Sensitivity of dilatometric measurement for sintering cycle

- Atmosphere control

- No wave disturbance

\section{Conclusion}

A new experimental device allowing pressure assisted resistive sintering and dynamic compaction has been developed. Adaptations have been done over a conventional SHPB for the combination of flash sintering and dynamic loading capabilities. A full automation of the device has been done which allows a good reproducibility of the experimental conditions for sintering conditions and endproducts. The device has been tested up to $1850{ }^{\circ} \mathrm{C}$ in temperature and $1000^{\circ} \mathrm{C} / \mathrm{min}$ for the heating rate. Copper powder has been sintered close to theoretical density in a relatively short time and in a reproducible manner. The process has been validated at different levels: reproducibility, precision, dilatometric densification, atmosphere controls and wave propagation.

\section{Acknowledgements}

P. Acquier would like to thanks the Direction Générale de l'Armement (DGA) under the convention number 201060083 and the Région Lorraine under the convention number DPRNT n ${ }^{\circ}$ 2011-209 for funding this PhD work. D. Lamy is also acknowledged for his fruitful help with the automation of the device.

\section{References}

1. R. Orru et al., 2009, Consolidation/synthesis of materials by electric current activated/assisted sintering, Mat. Sci. Eng. -Report, 63, 127-287

2. U. Anselmi-Tamburini et al., 2004, Spark plasma sintering and characterization of bulk nanostructured fully stabilized zirconia: Part I. Densification studies, J. Mater. Res., 19, 3255

3. C. Wang et al., 2001, Microstructure homogeneity control in spark plasma sintering of $\mathrm{Al}_{2} \mathrm{O}_{3}$ ceramics, J. Eur.Ceram.Soc., 31, 231-235

4. K. Hokamoto et al., " High temperature shock consolidation of hard ceramic powders », Physica B, Vol. 239, pp. 1-5, 1997

5. P. Skoglund, « High density PM parts produced by high velocity compaction », Powder metallurgy, Vol. 44, $\mathrm{N}^{\circ} 3$, pp. 199-201, 2001

6. M. Trécant et al., 1955, Dynamic compaction of calcium phosphate biomaterials, J. Mat. Sci Mater. Med., 6, 545-551

7. H.Å. Häggblad et al., 2005, Simulation of high velocity compaction of powders in a rubber mould with characterization of silicone rubber and titanium powder using a modified split Hopkinson set-up, Powder Technol., 154, 33-42 
8. A. Cezairliyan et al., 1971, Design and operational characteristics of a high-speed (millisecond) system for the measurement of thermophysical properties at high temperatures, Journal of research of the national bureau of standards-C. Engineering and instrumentation, Vol. $75 \mathrm{C}, \mathrm{N}^{\circ} 1,7-18$

9. Jankowiak et al., 2011, Validation of the KlepaczkoMalinowski model for friction correction and recommendations on Split Hopkinson Pressure Bar,
Finite Elements in Analysis and Design, 47, Issue 10, 1191-1208

10. T. Borvik et al., 2004, Perforation of al 5083H116 plates, Int. J. Impact Engng, 30, Issue 4, 367-384

11. S. Diouf, A. Molinari, 2012, Densification mechanisms in spark plasma sintering: Effect of particle size and pressure, Powder Technol., doi:10.1016/j.powtec.2012.01.005 